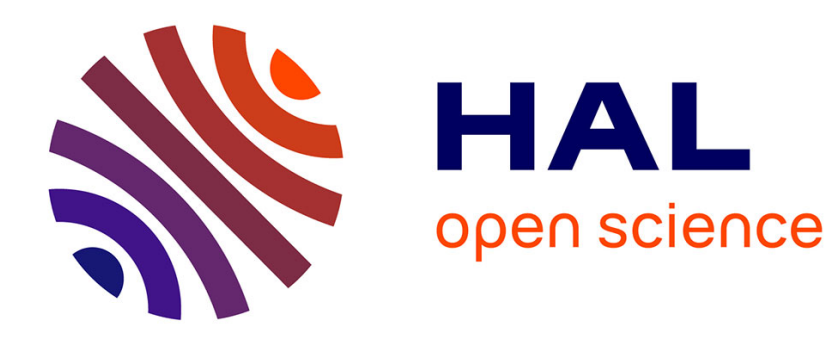

\title{
Water oxidation with inhomogeneous metal-silicon interfaces
}

Gabriel Loget

\section{To cite this version:}

Gabriel Loget. Water oxidation with inhomogeneous metal-silicon interfaces. Current Opinion in Colloid \& Interface Science, 2019, 39, pp.40-50. 10.1016/j.cocis.2019.01.001 . hal-02991335

\section{HAL Id: hal-02991335 \\ https://hal.science/hal-02991335}

Submitted on 5 Nov 2020

HAL is a multi-disciplinary open access archive for the deposit and dissemination of scientific research documents, whether they are published or not. The documents may come from teaching and research institutions in France or abroad, or from public or private research centers.
L'archive ouverte pluridisciplinaire HAL, est destinée au dépôt et à la diffusion de documents scientifiques de niveau recherche, publiés ou non, émanant des établissements d'enseignement et de recherche français ou étrangers, des laboratoires publics ou privés. 
4

5

6

7

\section{Abstract}

9

\section{Address}

\title{
Water oxidation with inhomogeneous metal-silicon interfaces
}

\author{
Gabriel Loget
}

Univ Rennes, CNRS, ISCR (Institut des Sciences Chimiques de Rennes)-UMR6226, F-35000 Rennes, France. E-mail: gabriel.loget@univ-rennes1.fr

$\mathrm{Si}$ is a prime candidate for manufacturing water-splitting photoelectrochemical cells, however, the stability of this material remains a serious bottleneck. This is particularly true for the photoanode, subject to severe deactivation mechanisms. So far, thin film homogeneity has been the paradigm in the quest for stable and efficient Si-based photoanodes, which involved the use of vapor deposition methods to produce conformal thin films ensuring $\mathrm{Si}$ protection and efficient catalysis during operation. Recent reports on $n$-Si/metal thin film junctions have highlighted the benefits of the junction heterogeneity, generated in situ. In addition, results obtained from $n$-Si photoanodes partially covered with discontinuous films of $\mathrm{Co}$ and $\mathrm{Ni}$ nanoparticles lately suggested that homogeneity is not a prerequisite to reach efficiency and stability. Such findings may open new protection routes for Sibased photoanodes, breaking with classical strategies and allowing the use of liquid phase modification methods such as electrodeposition.

\section{$\underline{\text { Abbreviations }}$}

ALD: atomic layer deposition cocat: co-catalyst

MIS: metal-insulator-semiconductor

NP: nanoparticle

OER: oxygen evolution reaction

PEC: photoelectrochemical cell

SC: semiconductor

SCL: space charge layer

$S i / p c$ : Si/co-catalytic protection layer

$\mathrm{Si} / \mathrm{p} / \mathrm{c}: \mathrm{Si} / \mathrm{protection}$ layer/co-catalyst

TCO: transparent conducting oxide 


\section{1-Introduction}

Although the integration of solar and wind energies in electrical grids is considerably growing worldwide, a major concern in employing these energy sources to a much larger extent is their intermittency and their diffuse geographic distribution. A solution to solve these two issues is the conversion of renewables into a carbon-free energy carrier that would allow the storage of energy and its distribution on site and on demand.[1] Hydrogen $\left(\mathrm{H}_{2}\right)$ has long been considered as a highly promising energy carrier to fulfill this challenge in a carbon-neutral system, so-called the "hydrogen economy".[2] In this view, solar and wind energies can be converted in $\mathrm{H}_{2}$, which would ensure in a perfect manner: energy storage as well as distribution and conversion in fuel cells, devices that readily convert $\mathrm{H}_{2}$ into electricity with water being the only by-product.[3] To this goal, $\mathrm{H}_{2}$ needs to be generated by the conversion of renewable energies through a zero-emission process. This is possible by coupling water electrolysis to a renewable source of energy to yield a completely clean and scalable process that generates highly pure $\mathrm{H}_{2}$ only from water, as described by the overall reaction (1).[4]

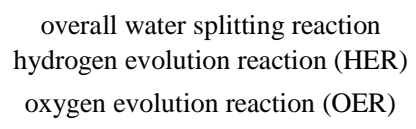

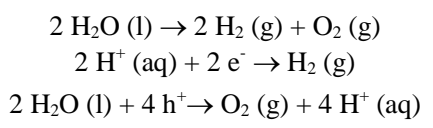

In water electrolysis, the electrical current that is applied between two electrodes, immersed in water, breaks the chemical bonds of the water molecule, thus generating $\mathrm{H}_{2}$ at the cathode (reaction (2)) and $\mathrm{O}_{2}$ at the anode (reaction (3)). The latter reaction, referred to as oxygen evolution reaction (OER), requires the transfer of four charge carriers (photogenerated holes when an $n$-type photoanode is used) and four protons and is often considered the bottleneck of water electrolysis as it requires a considerable amount of energy to be triggered. In the specific case of solar energy conversion, the transformation of sunlight energy via the electrolysis of water can be achieved by two strategies. First, conversion and electrolysis can be performed by two independent and separated commercial devices, i.e., a photovoltaic panel and an electrolyzer.[5,6] The second strategy combines both aspects on a single device, which can be done by interfacing sunlight-absorbing semiconductors (SCs) with an aqueous phase.[7-10] These systems are referred to as photoelectrochemical cells (PECs; Fig.1a) and have the advantage of being based on a simpler design that induces less potential losses and no power conditioning. Under sunlight irradiation the SC absorbs photons and convert them into charge carriers that are driven at the solid-liquid interface to react with water, generating pure $\mathrm{H}_{2}$ (reaction (2)) and $\mathrm{O}_{2}$ (reaction (3)). If the operation of relatively efficient PECs has been already demonstrated by different research groups,[11] several key challenges, such as their cost and their stability, need to be tackled to enable their practical use.[12] 

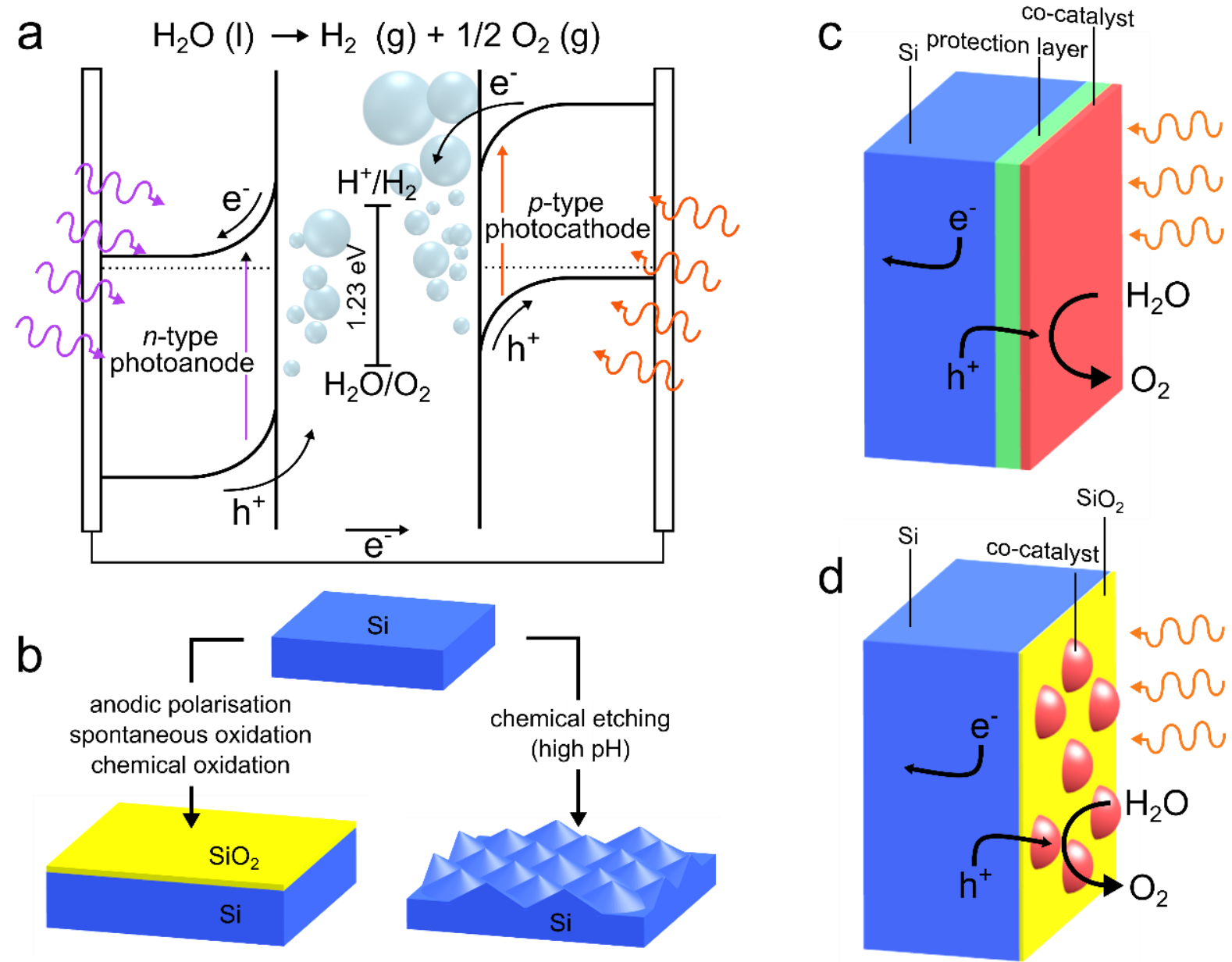

1

Fig.1. a) Scheme showing a PEC made of a SC photoanode and a SC photocathode connected by an ohmic contact. b) Scheme showing the deleterious mechanisms commonly occurring on Si photoelectrodes. c) Scheme of a conventional Si photoanode in the Si/protection layer/co-catalyst $(\mathrm{Si} / \mathrm{p} / \mathrm{c})$ configuration. d) Scheme of an inhomogeneous MIS photoanode.

To be employed in PECs, SC absorbers must have: a short band gap to absorb a considerable part of the sunlight and a high minority carrier lifetime. In this regard, silicon ( $\mathrm{Si}$ ) is particularly appealing because it meets these standards. Moreover, it is very abundant (the $2^{\text {nd }}$ element in the earth crust) and widely used in the microelectronics and photovoltaic industries, which would be a great advantage for technology transfer.[13] However, using Si as a photoelectrode, and particularly as a photoanode is very challenging, because of $i$ ) its slow charge transfer kinetics for OER (reaction (3)) and ii) its instability. The first problem is usually solved by integrating a high-efficiency co-catalyst (cocat) on the Si surface which collects the photogenerated holes and improves OER kinetics. In this frame, a particular interest is currently given to water electrolysis in alkaline medium because it allows employing highly efficient OER cocats, based on cheap and abundant materials such as Fe, Mn, Co, and Ni.[14] The latter issue (stability) has been the bottleneck for PEC manufacturing for long and is still the subject of intense research.[15-17] As shown in Fig.1b, Si is subject to two main deleterious mechanisms. The first one is the thermodynamic instability of $\mathrm{Si}$, which passivates upon immersion in 
aqueous solutions or when exposed to air with the spontaneous formation of an insulating native surface oxide. The anodic polarization of $\mathrm{Si}$ in aqueous medium intensifies this phenomenon which strictly prohibits the use of bare Si surface for OER.[18] The second degradation mechanism is $\mathrm{Si}$ etching, which happens readily at high $\mathrm{pH}$, and prevents its use in alkaline solutions.[18] Over the last decades, tremendous progress has been made on developing modification strategies to fabricate efficient and stable Si-based photoanodes.[15,16] In this short review, we will first briefly present the classical protection strategies based on the use of conformal layers and we will then focus on an emerging type of Si-based photoanodes, referred to as inhomogeneous metal-insulator-semiconductor (MIS). We will present the recent research on that topic and discuss the advantages and drawbacks of such systems.

\section{2- Conformally coated Si photoanodes}

2-1- One layer for stability, the other one for activity

The protection of Si-based photoanodes implies, in most cases, the introduction of a conformal protection layer between the SC and the cocat,[15,16] deposited by means of chemical vapor deposition, physical vapor deposition or atomic layer deposition (ALD).[19] In order to design an efficient protection layer, drastic considerations must be taken into account. First, the coating should allow a charge flow by means of its intrinsic conductivity or by tunneling, it should not deteriorate the energetics of the interface and it should not impede light absorption. It is worth noting that several interesting examples of Si-based tandem photoanodes operating with a wide band gap SC acting as the same time as an absorber and as a Si protection coating have been reported but fall outside our scope.[20-23] In contrast, this short review focuses on the most commonly-employed Si protection strategies, implying oxide layers that absorb a minimal portion of the incident light but ensure protection and promote charge transfer from Si to the cocat. We herein refer to this construct as the $\mathrm{Si} /$ protection layer/co-catalyst $(\mathrm{Si} / \mathrm{p} / \mathrm{c}$ ) configuration (Fig.1C). Note that in most of the cases, a thin $\left(<2 \mathrm{~nm}\right.$ ) interfacial $\mathrm{SiO}_{\mathrm{x}}$ layer is also present at the $\mathrm{Si}$ surface. So far, $\mathrm{TiO}_{2}$ has been the most employed material for $\mathrm{Si}$ protection. Several types of $\mathrm{TiO}_{2}$, prepared by different techniques and operating through different mechanisms, have been reported to be effective. Thick (up to $140 \mathrm{~nm}$ ) layers of amorphous[24] and crystalline[25] $\mathrm{TiO}_{2}$, deposited by ALD on $n$-Si and interfaced with Nibased cocats exhibit typical photovoltages of $\sim 400 \mathrm{mV}$ and could achieve OER with an unprecedented stability of 2,200 h.[26] In these systems, the solid $\mathrm{Si} / \mathrm{TiO}_{2}$ interface forms a buried junction[27] which controls the photovoltage and photogenerated holes are efficiently promoted through the "leaky" $\mathrm{TiO}_{2}$ via electronic defects to the Ni which forms an ohmic contact with $\mathrm{TiO}_{2}$ (Fig.2a).[24] Conversely, sputter-deposited crystalline $\mathrm{Ti}(5 \mathrm{~nm}) / \mathrm{TiO}_{2}(100 \mathrm{~nm})$ protection layers were reported to only conduct electrons and to form ohmic contacts with $n p^{+}$-Si homojunction.[28] Furthermore, thin ( 1-2 nm) 
ALD-deposited $\mathrm{TiO}_{2}$ conformal coatings can behave as tunnel layers, allowing an efficient transfer of photogenerated charges when interfaced with an Ir cocat layer in a MIS configuration (Fig.2b).[29,30] Annealing these junctions with forming gas reduces the trap states density at the Si interface, which considerably increases the photovoltage.[31] In addition, a recent report revealed that integrating an $n p^{+}$-Si buried junction in such a MIS system allows to maintain a high interfacial hole density and to achieve an unprecedented photovoltage value of $630 \mathrm{mV}$.[32] Besides, thin $(\sim 2 \mathrm{~nm})$ conformal dielectric films of ALD-deposited $\mathrm{HfO}_{2}[33]$ and $\mathrm{Al}_{2} \mathrm{O}_{3}[31,34]$ have also been employed as dielectric layers in MIS photoanodes. In particular, $\mathrm{Al}_{2} \mathrm{O}_{3}$, in contact with an Ir cocat film, behaves as a tunnel oxide, implying an exponential increase of the device resistance as a function of its thickness.[31] In another recent study, the introduction of a high work function metal layer between the $\mathrm{Al}_{2} \mathrm{O}_{3}$ tunnel layer and the Ni film allowed a considerable improvement of the barrier height, which resulted in photovoltages of $\sim 530 \mathrm{mV}$ for optimized photoanodes.[35] In this case, the authors found that the maximum photovoltage was not obtained for the thinnest dielectric layer and did not exclude the possibility of defect-mediated carrier transport through the $\mathrm{Al}_{2} \mathrm{O}_{3}$ film.[35] Finally, transparent conducting oxides (TCOs) have also been employed in the $\mathrm{Si} / \mathrm{p} / \mathrm{c}$ configuration. Only one example of a $p$-type TCO, $\mathrm{NiCo}_{2} \mathrm{O}_{4}$, has been reported in the $\mathrm{Si} / \mathrm{p} / \mathrm{c}$ configuration. This TCO was combined with an $n p^{+}$-Si buried junction and a NiFe-based OER cocat to perform OER for 72 h.[36] Mainly, classical $n$ type TCOs such as indium tin oxide (ITO)[37] or fluorine-doped $\mathrm{SnO}_{2}$ (FTO)[38] have been used for Si photoanode protection. In most of these reports, the TCOs have been employed with the aim of making non-rectifying electrical contact with a Si homojunction such as $n p p^{+}-\mathrm{Si},[37,38] n p^{+}-\mathrm{Si}$ [39] or with $\mathrm{Si}$ heterojunction cells,[40] in order to maintain the high photovoltage produced in the $\mathrm{Si}$ (Fig.2c). Thick (in the range of $100 \mathrm{~nm}$ ) layers of sputtered ITO and FTO deposited by spray pyrolysis can protect the underlying $\mathrm{Si}$ when interfaced with OER cocats. These reports have however highlighted the disadvantages of this approach which are: $i$ ) the downward band bending at the ITO/Si interface that needs to be circumvented by employing a highly doped $p^{+}$-Si layer at the interface in order to ensure an efficient hole collection,[37] ii) the low hole conductivity of these $n$-type oxides[39] and iii) the low stability of ITO at harsh pH.[41] A recent very interesting report demonstrates that thick $(\sim 100 \mathrm{~nm})$ layers of spray-deposited $\mathrm{SnO}_{\mathrm{x}}$ on $n$-Si produces a high barrier heterojunction that can be employed for promoting OER with a photovoltage of $\sim 620 \mathrm{mV}$ for $100 \mathrm{~h}$ when interfaced with highly-active OER cocats.[42] 

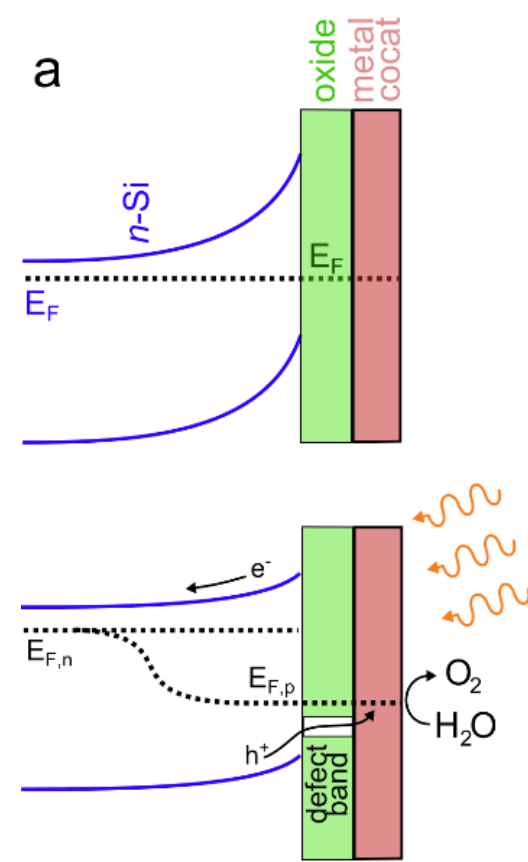
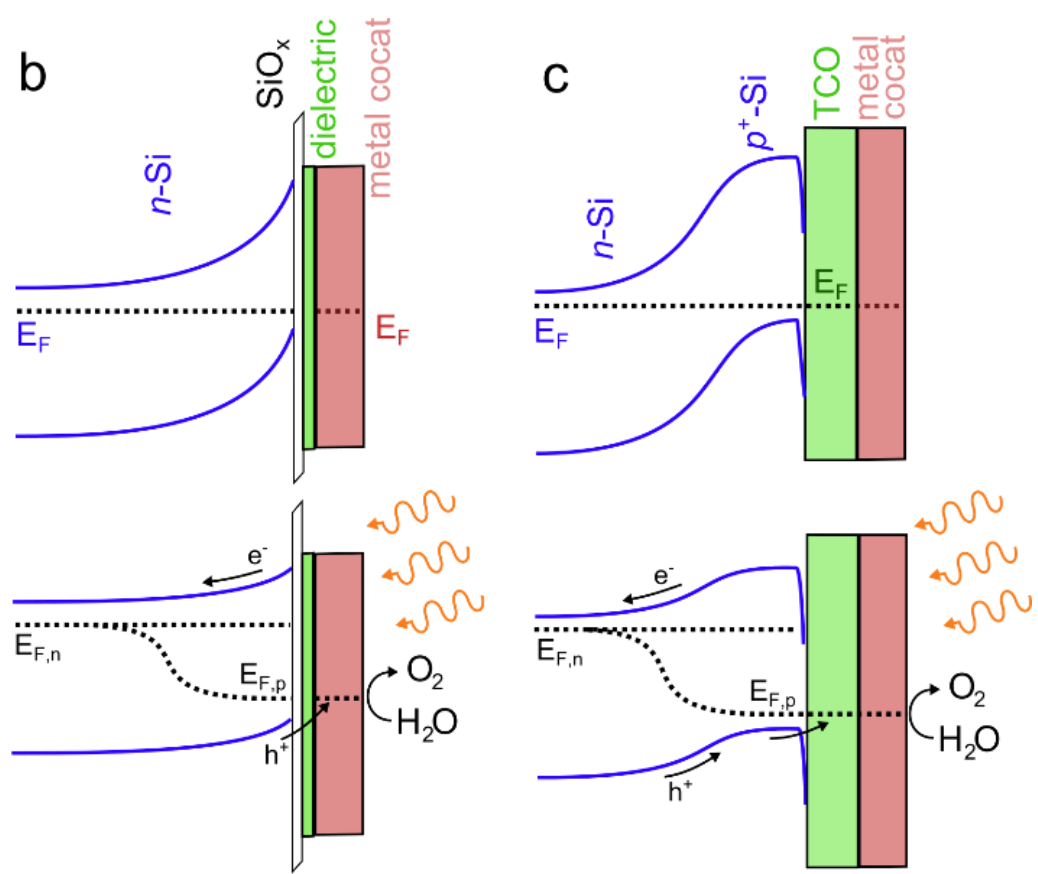

Fig.2. Schematic band diagrams showing the charge transfer mechanisms occurring for the three main Si/p/c configuration reported, after equilibration in the dark (top row) and in photoelectrochemical operation (bottom row), the Fermi level $\left(E_{F}\right)$ of each component, as well as the hole $\left(E_{F, p}\right)$ and electron $\left(E_{F, n}\right)$ quasi-Fermi levels are represented by dashed lines. a) The barrier height is imposed by the heterojunction formed between $n$-Si and the thick oxide protecting layer, the cocat forms an ohmic contact with the oxide. The charge transfer from Si to the cocat is achieved by charge conduction through the oxide layer (here, by hole conduction through defect bands). b) The barrier height is imposed by the Schottky junction between $n$-Si and the metal cocat. This configuration is referred to as MIS junction when the charge transfer from $\mathrm{Si}$ to the cocat occurs via tunneling through a thin dielectric film. c) The barrier height is controlled by the buried $n p^{+}$-Si homojunction. Efficient charge transfer at the $\mathrm{Si} / \mathrm{TCO}$ interface is usually promoted by employing a highly doped $\mathrm{Si}$ interfacial layer to reduce the thickness of the interfacial space charge layer.

\section{2-2- Combining protection and activity in a single layer}

An alternative and highly beneficial strategy that has also been employed to decrease the manufacturing costs consists in employing a coating material that acts as a Si protection layer and, as the same time, as a cocat. We refer here to this configuration as $\mathrm{Si} / \mathrm{co}$-catalytic protection layer $(\mathrm{Si} / \mathrm{pc})$. Note that in such a configuration, even though only one layer is deposited over the $\mathrm{Si}$ surface, an additional conditioning step of the surface is often required to generate catalytic species on that layer, sometimes that step is spontaneously occurring during OER. Therefore, if the $\mathrm{Si} / \mathrm{pc}$ is more attractive than the $\mathrm{Si} / \mathrm{p} / \mathrm{c}$ configuration in terms of fabrication, these systems are, in fine, relatively identical from a structural point of view. Interestingly, only one recent report has described a Si/pc photoanode operating at low $\mathrm{pH}$ (employing an Ir-based film on $n p^{+}$-Si).[43] In contrast, the use of the $\mathrm{Si} / \mathrm{pc}$ configuration for photoanodes operating at high $\mathrm{pH}$ has been lately investigated by several groups. If this may first seem unexpected considering the fact that alkaline media are harsher for Si (Fig.1b) it can be explained by the fact that these conditions allow employing abundant OER-active materials (based on $\mathrm{Fe}, \mathrm{Mn}, \mathrm{Co}$, and Ni).[14] So far, very little has been reported on $\mathrm{FeO}_{\mathrm{x}}[44]$ and $\mathrm{MnO}_{\mathrm{x}}[45]$ layers, which, when employed as films in the range of $\sim 10 \mathrm{~nm}$ on $n$-Si, are known to promote OER 
with photovoltages partially controlled by the liquid phase. [44,45] More work has been focused on $\mathrm{CoO}_{\mathrm{x}}$ layers, for instance, thin $(\sim 2-5 \mathrm{~nm}) \mathrm{CoO}_{\mathrm{x}}$ layers deposited by plasma-enhanced ALD or sputtering have been employed to protect crystalline[46] or amorphous Si homojunctions.[47] In particular, annealing these films allowed to generate a catalytically-active $\mathrm{Co}(\mathrm{OH})_{2}$ outer layer on the top of a dense and highly impermeable $\mathrm{Co}_{3} \mathrm{O}_{4}$ which was very efficient on $n p^{+}-\mathrm{Si}$.[48] Thicker $(\sim 50$ $\mathrm{nm})$, ALD-deposited $\mathrm{CoO}_{\mathrm{x}}$ coatings have been also employed on $n$-Si with which they form a heterojunction affording a $\sim 570 \mathrm{mV}$ photovoltage and can protect the system for 100 days of continuous electrolysis.[49] Most of the Si/pc systems are based on Ni layers. If it has been reported that $\sim 75 \mathrm{~nm}$-thick transparent and antireflective $\mathrm{NiO}_{\mathrm{x}}$ layers (deposited by reactive sputtering) generate a rather low barrier heterojunction with $n$-Si (and can only afford a $\sim 200 \mathrm{mV}$ photovoltage for OER),[50] it can be considerably improved by incorporating a $\mathrm{CoO}_{\mathrm{x}}$ interlayer.[51] $\mathrm{Such} \mathrm{NiO}_{\mathrm{x}}$ coatings can be employed as conductive, protective and catalytic layers for crystalline[50] and amorphous[52] Si homojunctions as well as Si heterojunctions.[52] In addition, sputtered, 50 nmthick $\mathrm{NiO}[53]$ and $\mathrm{NiCoO}_{\mathrm{x}}[54]$ have been used as $p$-type conductive catalytic layers to protect $n p^{+}$and back-illuminated $n^{+} p p^{+}$-Si homojunctions. It has been clearly shown that the electrochemical performance of these layers is affected by the presence of Fe in solution and have been employed for 300 [53] and $72 \mathrm{~h}$ [54] of operation, respectively. It is worth noting that the deliberate or unintentional doping of Ni-based coatings with $\mathrm{Fe}$ atoms (that can originate from the materials employed during water electrolysis experiments) is quite important as $\mathrm{Fe}$ is known to strongly affect the catalytic performance of Ni-based catalysts, for instance, it integrates into the highly-active OER phase $\mathrm{NiOOH}$ to produce $\mathrm{Ni}(\mathrm{Fe}) \mathrm{OOH}$, that can lead to an improvement or a degradation of the OER thermodynamics and kinetics, depending on the Fe content.[77] Thin Ni metal layers, deposited by e-beam or thermal evaporation on $n$-Si, have also been employed for manufacturing $\mathrm{Si} / \mathrm{pc}$ photoanodes. The first publication on this system reported the considerable effect of the layer thickness on the photoelectrochemical properties as well as the importance of the interfacial $\mathrm{SiO}_{\mathrm{x}}$ layer.[55] Optimal performance was obtained for $2 \mathrm{~nm}$-thick films which afforded $\sim 500 \mathrm{mV}$ photovoltage and $12 \mathrm{~h}$ stability at $\mathrm{pH} 14$. This photovoltage value is much higher than the one expected for a classical $n$ $\mathrm{Si} / \mathrm{SiO}_{\mathrm{x}} / \mathrm{Ni}$ Schottky barrier and this striking behavior, obtained for such a simple system, has triggered a broad interest. In particular, it has been recently shown that the failure is caused by the thickening of the $\mathrm{SiO}_{x},[56]$ associated with the permeation of the $\mathrm{Ni} / \mathrm{NiO}_{\mathrm{x}}$ during operation. The $n-\mathrm{Si} / \mathrm{SiO} \mathrm{x}_{\mathrm{x}} / \mathrm{Ni}$ photoanodes have been first described as a classical MIS device (Fig.2b) where the partially oxidized $\mathrm{Ni}$ layer homogeneously coat $\mathrm{Si}$, but, with a particular case for ultrathin layers $(2 \mathrm{~nm})$ where $n$-Si equilibrates with both the $\mathrm{Ni}$ and the liquid phase, affording the higher built-in potential.[55] If this description has been confirmed for thick Ni layer,[57,58] a recent study employing the dual working electrode technique (which allows decoupling the electrochemical activity of the coating from the overall photoanode response) allowed to get more insights on the operating mechanism of $n$-Si photoanodes coated with ultrathin Ni layers.[58] First, it revealed that the junction controlling the 
photovoltage is buried and dynamic as it is not influenced by the solution potential but evolves during electrochemical conditioning. However, it clearly pointed out that the activity of this system was not entirely controlled by the chemical transformation of $\mathrm{Ni}$ to a more active cocat phase during conditioning, but is mostly due to a structural change at the solid/solid interface.[58] It was proposed that during activation the majority of the $\mathrm{Ni}^{0}$ layer was converted into $\mathrm{Ni}(\mathrm{OH})_{2}$ which is $\mathrm{OER}$ active, but, more importantly, permeable to the electrolyte, causing the anodization of $\mathrm{Si}$ to insulating $\mathrm{SiO}_{\mathrm{x}}$ in the regions of contact with the electrolyte. Besides, X-ray photoelectron spectroscopy revealed the presence of $\mathrm{Ni}^{0}$ remaining in the film. These elements allowed a better understanding of this surface, considered now as an inhomogeneous buried junction operating in the pinch-off regime, as shown in Fig.3c (note that pinch-off will be described in section 3-2).

\section{3- Inhomogeneously coated Si photoanodes}

3-1- Inhomogeneous photoanodes not in the pinch-off regime

\section{3-1-1- Photoanodes patterned by vapor deposition}

Using arrays of micrometer-sized cocat patterns in contact with $\mathrm{Si}$ instead of conformal films can be advantageous for reducing optical losses and improving light absorption by the SC. Furthermore, the protection of the uncoated surface can be addressed quite conveniently by oxidizing the uncovered $\mathrm{Si}$ to generate a passive $\mathrm{SiO}_{\mathrm{x}}$ layer. Several interesting examples of inhomogeneous $\mathrm{Si}$ photoanodes patterned with arrays of micrometer-sized cocat patches (larger than the SCL, thus not exhibiting pinch-off, see section 3-2), fabricated by a combination of clean room and physical vapor deposition techniques have been reported. For instance, $\mathrm{Ni}$ deposited directly on $n$ - or $n p^{+}-\mathrm{Si}(111)$, can be employed as micro-sized catalytic patches to promote OER for durations exceeding $100 \mathrm{~h}$ at $\mathrm{pH}$ 14.[59] In this case, the anodic $\mathrm{SiO}_{\mathrm{x}}$ generated in situ protects the uncoated Si during operation. This design has been employed for monitoring the local $\mathrm{O}_{2}$ production and identifying the photoanode failure modes. Another strategy consists in patterning a Si surface that is initially passivated with a thick $\mathrm{SiO}_{2}$ thermal oxide layer to ensure a long-term stability. This concept has been employed with arrays of $\mathrm{Pt}$ and Ti/Ni planar disks[60] as well as nanostructured $\mathrm{Au} / \mathrm{Ni}$ and $\mathrm{Au} / \mathrm{NiFe}$ micro-sized islands[61] on $n p^{+}-\mathrm{Si}$ for OER at alkaline $\mathrm{pH}$. In these cases, however, the use of reactive ion etching is required to regioselectively remove the $\mathrm{SiO}_{2}$ before metal deposition. An attractive and original method based on localized dielectric breakdown can be employed to circumvent this technical issue. It has been shown that micrometer-sized islands of a NiFe-based cocat, deposited by e-beam evaporation directly on a $30 \mathrm{~nm}$-thick thermally grown $\mathrm{SiO}_{2}$, can be electrically contacted to the underlying $n$-Si by exceeding the breakdown voltage. Such a procedure allows creating a conducting filament between the cocat island and the SC that promotes the conduction of photogenerated holes through the dielectric.[62] 
Almost all photoanode designs discussed in the previous sections require high vacuum deposition techniques. Alternative solution-based methods would not be only attractive from a financial point of view but also because they may offer new possibilities in terms of coating composition or morphology. Pioneer research has been carried out in that direction using sol-gel processes to protect $n$-Si but resulted in limited stability.[63] Modification techniques based on electrochemistry, such as electrodeposition, seems particularly attractive because they are usually low-cost, can be employed to deposit a wide variety of materials on conductors or SCs and they usually allow a precise control over the film thickness. Even though electrochemical techniques such as electrodeposition and anodization were early suggested to prepare Si-based photoanodes,[64] they have been scarcely employed so far, probably due to the well-established instability of Si surfaces in liquid electrolytes and the fear of generating a fully-insulating $\mathrm{SiO}_{\mathrm{x}}$ layer during surface modification (section 1). In addition, high vacuum techniques are usually preferred as they typically produce high density and pinhole-free coatings, which is not always the case for electrodeposited layers, at the expense of long-term stability. However, in view of the recent knowledge on the Si/electrolyte interface and the interest given on the pinch-off effect (see section 3-2), it does not seem worthless to explore the use of electrochemical processes applied to the manufacturing of Si-based photoanodes, and experimental works readily revealed that such methods could lead to photoanodes with remarkable performance. In the following, we will first describe the very few examples using electrochemical methods (mostly electrodeposition) to fabricate Si-based photoanodes that are not operating in the pinch-off regime and we then will discuss the fabrication of pinched-off photoanodes (next section). Recently, electrodeposition of inhomogeneous metal layers has been employed to produce photoanodes in the $\mathrm{Si} / \mathrm{pc}$ configuration to protect Si buried homojunctions. Thin $(\sim 6 \mathrm{~nm})$ and discontinuous NiFe metal films exhibited great performance on $n p^{+}-\mathrm{Si}$, which afforded a photovoltage of $620 \mathrm{mV}$ and a stability $>12 \mathrm{~h}$ at $\mathrm{pH}$ 14.[65] In addition, the scalability of electrochemical processes applied to Si-based materials has been demonstrated by a recent publication that reported the electrodeposition of large and flexible $\mathrm{NiFe}$ films and their subsequent anodization via a continuous roll-to-roll process to form a highly active OER cocat layer. Its integration to an amorphous Si solar cell has allowed oxidizing water in $1 \mathrm{M}$ $\mathrm{KOH}$ from on onset potential as low as $+0.6 \mathrm{~V} v s$ RHE and an operation time of $12 \mathrm{~h}$.[66]

\section{$\underline{\text { 3-2- Pinched-off photoelectrodes }}$}

The pinch-off phenomenon has been first introduced in the field of solid state physics as a way to explain the behavior of inhomogeneous Schottky junctions.[67] In such a typical system, the SC surface is brought in contact with two phases leading to an inhomogeneity of the depletion region. If these systems were previously typically considered as separated heterojunctions operating in parallel, several results revealed the non-validity of this model when the characteristic size of one junction became comparable or fell below the thickness of the space-charge layer (SCL).[68] This size effect 
has been attributed to the pinch-off effect in the early eighties,[69] and was rationalized in the nineties.[70] The pinch-off effect is illustrated by Fig.3b in the case of a low-doped $n$-Si surface that contains two interfaces of different barrier heights: a low barrier region, spatially distributed in areas of a characteristic size smaller than the SCL and a high barrier region that covers the rest of the $\mathrm{Si}$ surface. In this size regime, the depletion of majority carriers required to reach equilibrium at the high barrier contact extends under the low barrier contact, affecting the local band bending (creating a "saddle point" under the high barrier-region) and increases the overall barrier height (Fig.3a vs Fig.3b).[67] The pinch-off effect has been early observed in the case of inhomogeneous $n$-Si/metal junction in contact with liquid phases.[71,72] Notably, a study has shown that the behavior of $n$-Si covered with Ni patches immersed in an organic electrolyte containing a reversible redox couple (to create a high barrier Si/electrolyte region at the Ni-free regions) behaves in good agreement with the pinch-off theoretical predictions when the Ni patch size was below $100 \mathrm{~nm}$.[73] It is obvious that the pinch-off effect can be very advantageous to fabricate Si-based OER photoanodes and compensate the losses caused by Fermi-level pinning, often generated at SC/metal junctions. In addition, it combines very well with the hydrogenated $\mathrm{Si}(\mathrm{Si}-\mathrm{H})$ surface for which surface energetics can be finely tuned by chemical surface functionalization.[74] More importantly, interfacial $\mathrm{SiO}_{\mathrm{x}}$ can be easily employed to passivate $\mathrm{Si}$ and generate a high barrier region with a low density of interface states. Thus, pinched-off photoelectrodes could be, in principle, easily fabricated by partially modifying $\mathrm{Si}$ with small particles of an appropriate metal and oxidizing the non-coated area. In addition to the high photovoltage generated by the effect, in this configuration, the photogenerated holes will mainly flow through the less resistive pathway and will be collected at the metal particles where they can be employed for OER. 
a

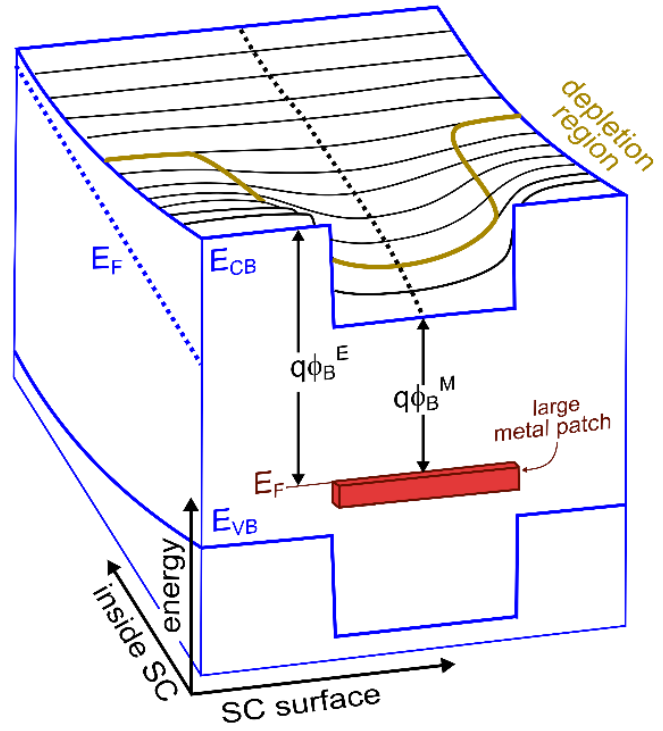

C

alkaline electrolyte

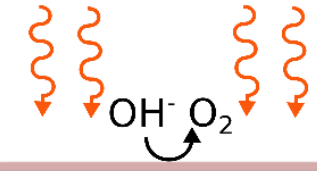

b
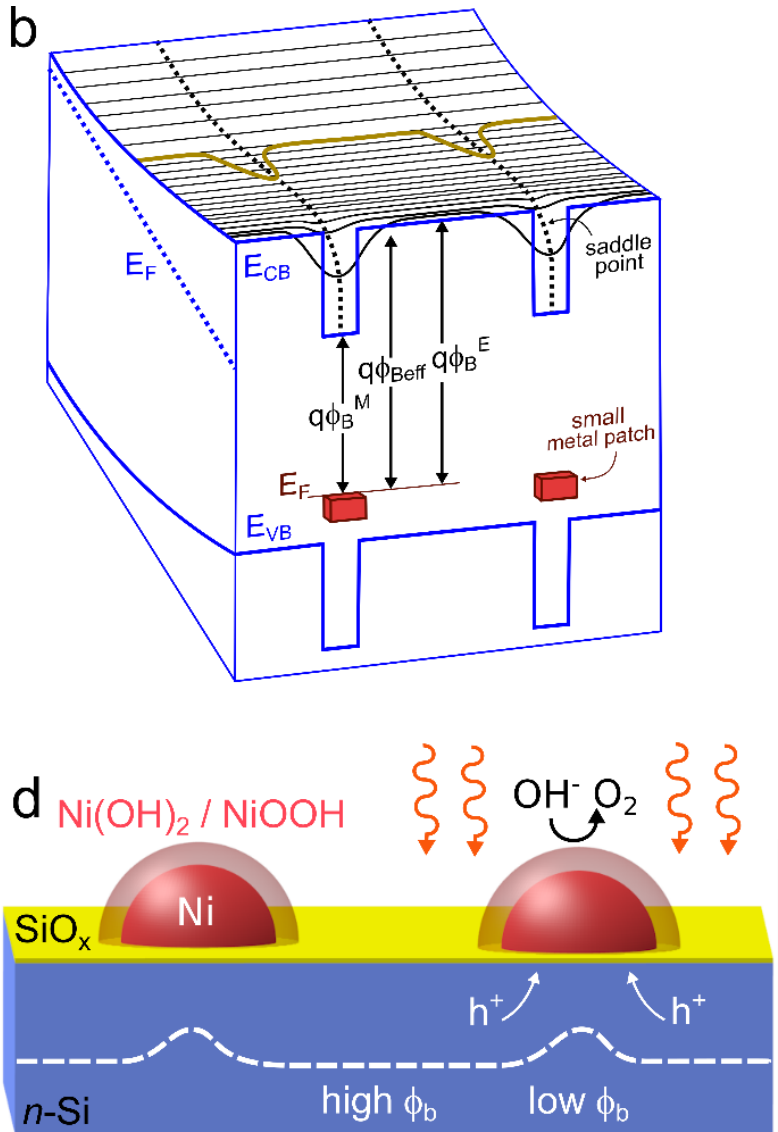

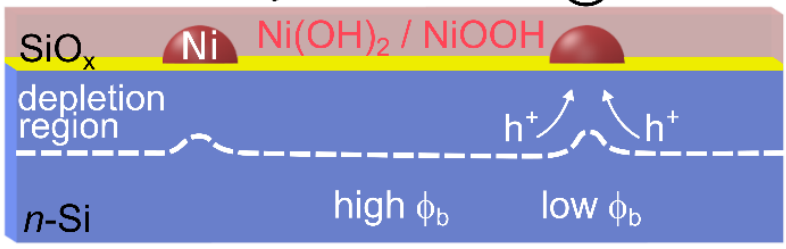

Fig.3. a,b) Schematic energy diagrams, adapted from Nakato et al. (reference[72]), for a $n$-type SC in contact with a metal patch that produces a low barrier height $\left(\phi_{\mathrm{B}}{ }^{\mathrm{M}}\right)$ region and a second phase that produces a high barrier height $\left(\phi_{\mathrm{B}}{ }^{\mathrm{E}}\right)$ region ( $q$ is the elementary charge). In a) the metal patch is large and in b) the metal patch is small with respect to the depletion width. In blue are represented the energies of the Fermi level ( $E_{F}$ dotted line), the valence band $\left(E_{\mathrm{VB}}\right)$ and the conduction band $\left(\mathrm{E}_{\mathrm{CB}}\right)$ of the $S C$ and in red is represented the $\mathrm{E}_{\mathrm{F}}$ of the metal. The full black lines represent the distribution of the potential barrier inside the SC, the dotted black line represent the potential distribution under a metal patch and the dark yellow line represent the depletion region. In Fig.3b, because of the small size of the metal patches, the surface is pinched-off and the effective barrier height ( $\left.\phi_{\text {Beff }}\right)$ is much higher than $\phi_{\mathrm{B}}^{\mathrm{M}}$. c) Scheme, adapted from Boettcher et al. (reference [58]), showing the interface of an $n$ $\mathrm{Si} / \mathrm{SiO}_{\times} / \mathrm{Ni}$, where the $\mathrm{Ni}$ is ultrathin. During operation, the $\mathrm{Ni}$ surface is partially converted in catalytic and permeable $\mathrm{Ni}(\mathrm{OH})_{2} / \mathrm{NiOOH}$, allowing Si to oxidize and to form a $\mathrm{SiO}_{x}$ passive layer. This surface is thought to be pinched-off (as in Fig.3b), explaining the high value of obtained photovoltages. d) Scheme showing the interface of a pinched-off inhomogeneous MIS photoanode fabricated by electrodeposition of $\mathrm{Ni}^{0}$ on $n$-Si (section 3-3).

\section{3-3- Pinched-off photoanodes prepared by electrochemical methods}

Typical cathodic electrodeposition of metals occurs via a nucleation-growth mechanism which makes this method particularly relevant for the decoration of an $n$-Si surface with dispersed metal nanoparticles (NPs), causing a minimal light interference and inducing the pinch-off phenomenon. The first example of a rather stable ( $2 \mathrm{~h}$ at $\mathrm{pH} 14$ and $25 \mathrm{~h}$ at $\mathrm{pH} 9)$ photoanode composed of nanometersized metal electrodeposits on $n$-Si was reported in 2015. Here, inhomogeneous Co islands were reported to generate high photocurrents $\left(>30 \mathrm{~mA} \mathrm{~cm}^{-2}\right)$ and surprisingly high photovoltages, greater than the one obtained with conformal $n-\mathrm{Si} / \mathrm{CoSi}{ }_{2}$ and $n-\mathrm{Si}_{/} / \mathrm{SiO}_{x} / \mathrm{Co}$ solid junctions.[75] If the authors 
could not ascribe this behavior to a precise physical phenomenon, they clearly demonstrated the importance of $i$ ) the Co inhomogeneity to generate different barrier heights and ii) the $\mathrm{SiO}_{\mathrm{x}}$ layer, and, showed that the photovoltage was independent of the solution potential. In addition, they also suggested that the $\mathrm{CoOOH}$ catalytic layer, formed around the $\mathrm{Co}^{0}$ particles could play a role in the interface energetics and may improve charge extraction.[75] This report set an important landmark as it showed for the first time that electrodeposited inhomogeneous coatings can be used to fabricate photoanodes with remarkable performance without employing a buried Si homojunction and a homogeneous protection layer. Two years later, we have demonstrated that $n$-Si modified with dispersed hemispherical Ni NPs by cathodic electrodeposition can be employed to trigger OER in alkaline media with an onset potential more negative than the $\mathrm{O}_{2} / \mathrm{H}_{2} \mathrm{O}$ formal potential and a higher stability[76] than those previously reported for Co-based electrodes.[75] We have also evidenced a strong correlation between the $\mathrm{Ni}$ coverage and the photoelectrochemical performance. Indeed, the highest photovoltages and photocurrents were obtained for low Ni coverage while an increase of the $\mathrm{Ni}$ loading decreased the performances (but increased the stability). The electrodes fabricated using this method exhibit photovoltages that can exceed $400 \mathrm{mV}$ and can operate for more than $10 \mathrm{~h}$ at $\mathrm{pH}$ 14.[76] Actually, the behavior of these photoanodes is very similar to that reported for ultrathin conformal layers of $\mathrm{Ni}$ (described in section 2-2, see Fig.3c), which suggests that both of them are operating in the pinch-off regime, as shown in Fig.3d.[55] We recently reported the effect of photoelectrochemical activation, which, by producing a catalytic $\mathrm{Ni}(\mathrm{OH})_{2} / \mathrm{NiOOH}$ shell, doped with $\mathrm{Fe}$ (thus referred here as $\left.\mathrm{Ni}(\mathrm{Fe})(\mathrm{OH})_{2} / \mathrm{Ni}(\mathrm{Fe}) \mathrm{OOH}\right)$, around the $\mathrm{Ni}^{0}$ particles, can considerably improve the OER kinetics.[77] In addition, a stability study revealed that the protection originates from the oxidation of the uncoated $\mathrm{Si}$ which readily passivates the $\mathrm{Si}$ exposed to the solution and protects it, in operando, from alkaline etching. Besides, unexpected stability was reported at the open circuit potential and it was found that the presence of the Ni particles on the surface slowed down electrode deactivation with a more pronounced effect under illumination.[77] After our initial report, several groups have employed the same strategy to fabricate pinched-off photoanodes. For instance, the effect of annealing was studied and the thermal oxidation of the Ni particles was found to improve the photovoltage and the photocurrent, which was attributed to the partial conversion of Ni to a $p$-type $\mathrm{NiO}_{\mathrm{x}}$ that increased the pinched-off barrier height underneath the Ni NPs.[78] An interesting study has reported the effect of the thickness of the $\mathrm{Ni}(\mathrm{OH})_{2}$ layer grown on the Si NPs. In this case, the $\mathrm{Ni}(\mathrm{OH})_{2}$ was electrochemically deposited over the Ni particles,[79] which produced essentially the same effect as electrochemical conditioning,[77] except that the Ni core remained unaffected during deposition. It was shown that the presence of the $\mathrm{Ni}(\mathrm{OH})_{2}$ coating considerably improved the open circuit photovoltage and therefore the performance for OER. $\mathrm{Ni}(\mathrm{OH})_{2}$ was assumed to be responsible for the increase in the overall barrier height due to a $p$-type nature,[79] which may be the subject of debate because $\mathrm{Ni}(\mathrm{OH})_{2}$ is typically insulating and electrolyte permeable.[80] Also, this electrodeposition process has been applied to microstructured $n$-Si.[81] Recently, we have reported the 
integration of these pinched-off photoanodes in an "all Si"-based monolithic photoelectrochemical cell that quantitatively produced $\mathrm{H}_{2}$ directly under solar illumination,[82] showing that this type of photoanode can be employed for unassisted solar water splitting.

Furthermore, owing to the very negative redox potential of the $\mathrm{SiO}_{2} / \mathrm{Si}$ couple, bare $\mathrm{Si}$ can be directly employed to reduce certain metal salts at its surface without applying an external bias. Although being of an electrochemical nature, this process, referred to as electroless deposition, is spontaneous and does not require the use of a potentiostat. It has been recently employed to spontaneously modify $n$-Si with Ni particles,[83] leading to photoanodes with a considerably different structure as, in this case, a submicrometer-thick porous $\mathrm{SiO}_{2}$ layer comprising conductive $\mathrm{Ni}$ filaments was formed between the $\mathrm{Si}$ and the $\mathrm{Ni}$ cocat during the electroless deposition process. Interestingly, the reported photoelectrochemical properties of these photoanodes were very similar to those obtained by $\mathrm{Ni}$ cathodic electrodeposition, suggesting that the pinch-off effect might also happen at the $\mathrm{Si} /$ inhomogeneous $\mathrm{Ni}-\mathrm{SiO}_{2}$ interface despite structural differences and the interface complexity.

\section{4- Concluding remarks}

Si-based water-splitting PECs could potentially play a role in a sustainable energy economy, however, this would be only feasible if the current bottlenecks that are: $i$ ) their cost and ii) their stability are successfully addressed. In order to overcome this challenge, considerable research effort has been made on Si-based photoanodes, that suffer from serious deleterious mechanisms, leading to their fast deactivation (section 1). So far, homogeneity has been the paradigm in the search for stable and efficient Si-based photoanodes, which involved the use of physical vapor deposition, chemical vapor deposition or ALD to produce conformal, pinhole-free, oxide thin films ensuring Si protection and efficient catalysis during operation (section 2). The recent progress in this area has been considerable, as demonstrated by several reports showing the operation of highly stable Si-based photoanodes with operation time in the range of $100 \mathrm{~h}$ and up to more than 2,000 h.[26]

On the other hand, recent reports on photoanodes based on the MIS configuration have shown that, when properly engineered,[32,35] such interfaces can exhibit excellent OER performance, approaching the one obtained with buried Si homojunctions. The interest of these studies is twofold as they may potentially decrease the process costs related to the fabrication of Si-based photoanodes by avoiding the need for homojunctions and also because they point out principles that may be transposed to other SC materials, for which homojunctions cannot be created. A remarkable example in the frame of $\mathrm{Si} /$ metal junction is the $n$-Si/Ni junction,[55] which is prepared by coating $n$-Si with an ultrathin layer of Ni. Although this junction is initially homogeneous, a recent experimental study has shown that its outstanding performance originates from its inhomogeneity, which is generated during operation.[58] It is, thus, intriguing to note that considerable improvement can arise from the 
transformation of a homogeneous phase to a highly inhomogeneous (and partially electrolytepermeable) phase while keeping a decent stability. Such findings should trigger the interest in novel forms of protection, breaking with the classical strategies, which could involve simpler liquid-phase fabrication methods.

In this context, electrochemical modification methods may be perfect candidates for preparing efficient water-splitting photoanodes. This has been recently suggested by recent reports on randomlydispersed Co[75] and Ni[76,77] NP arrays, generated by electrodeposition on $n$-Si. In these systems, a large portion of the $\mathrm{Si}$ is exposed to the electrolyte, which induces its anodic passivation under operation and favors pinch-off (section 3-2), promoting high built-in voltages. The simplicity of Ni electrodeposition has quickly driven several research groups to employ this method successfully which has led to stability in the range of $10 \mathrm{~h}$ at $\mathrm{pH} \sim 14[76]$ and up to $300 \mathrm{~h}$ at $\mathrm{pH}$ 9.[79] Such a stability could first seem unexpected considering such corrosive environments for $\mathrm{Si}$, and that the largest $\mathrm{Si}$ part is covered by nothing but its anodic oxide. If these unexpected recent reports are exciting, the performance of inhomogeneous photoanodes manufactured this way is still far from their conformal, oxide-coated, counterparts in terms of photovoltage[42] but also stability.[26] Nevertheless, it is expected that considerable progress could be obtained through a better understanding of the pinch-off

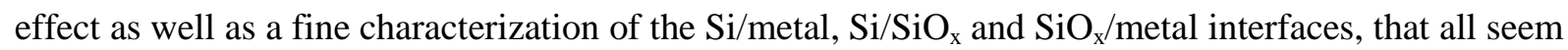
to play an important role for photovoltage generation and stability.[77] A detailed comprehension of each component of these complex inhomogeneous surfaces may open doors for improvement of the photoanode lifetime. It is envisioned that ameliorations are within reach by applying simple chemical treatments, for instance, improving the oxide quality or generating interfacial silicides. Electrodeposition conveniently allows triggering layer by layer modifications at the cocat level (allowing the generation of core-shell structures) and thus, is expected to quickly lead to progress in the optimization the catalytic aspect of these photoanodes.[77,79,84] In addition, progress will probably arise from studying other important considerations such as cocat geometry, adhesion, and surface distribution. Attention should also be paid to a crucial but often neglected aspect that is the photoanode stability when unbiased. Indeed, all photoanodes described in this short review are expected to be integrated into water-spitting PECs where they will be subject to dark cycles (typically overnight) which may be strongly deleterious to, especially at high $\mathrm{pH}$.

\section{Funding}

This work is partly funded by ANR (project EASi-NANO, ANR-16-CE09-0001-01)

\section{Acknowledgments}

Dr. Bruno Fabre is warmly acknowledged for fruitful discussions.

\section{$\underline{\text { References }}$}




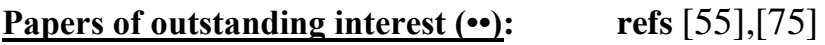

2 1. Elliott D: A balancing act for renewables. Nat Energy 2016, 1:15003.

32 . Bockris JO: A hydrogen economy. Science 1972, 176:1323-1323.

3. Stamenkovic VR, Strmcnik D, Lopes PP, Markovic NM: Energy and fuels from electrochemical

4. Xiang C, Papadantonakis M, Lewis NS: Principles and implementations of electrolysis systems for water splitting. Mater Horizons 2016, 3:169-173.

5. Cox CR, Lee JZ, Nocera DG, Buonassisi T: Ten-percent solar-to-fuel conversion with nonprecious materials. Proc Natl Acad Sci USA 2014, 111:14057-14061.

6. Luo J, Im J-H, Mayer MT, Schreier M, Nazeeruddin MK, Park N-G, Tilley SD, Fan HJ, Grätzel M: Water photolysis at $\mathbf{1 2 . 3 \%}$ efficiency via perovskite photovoltaics and earth-abundant catalysts. Science 2014, 345:1593-1596.

7. Fujishima A, Honda K: Electrochemical photolysis of water at a semiconductor electrode. Nature 1972, 238:37-38.

8. Gerischer H: Solar photoelectrolysis with semiconductor electrodes. In Solar Energy Conversion: Solid-State Physics Aspects. Edited by Seraphin BO. Springer; 1979:115-172.

9. Walter MG, Warren EL, McKone JR, Boettcher SW, Mi Q, Santori EA, Lewis NS: Solar water splitting cells. Chem Rev 2010, 110:6446-6473.

10. Sivula K, van de Krol R: Semiconducting materials for photoelectrochemical energy conversion. Nat Rev Mater 2016, 1:15010.

11. Ager JW, Shaner MR, Walczak KA, Sharp ID, Ardo S: Experimental demonstrations of spontaneous, solar-driven photoelectrochemical water splitting. Energy Environ Sci 2015, 8:2811-2824.

12. Shaner MR, Atwater HA, Lewis S, Mcfarland EW: A comparative technoeconomic analysis of energy. Energy Environ Sci 2016, 9:2354-2371.

13. Sun K, Shen S, Liang Y, Burrows PE, Mao SS, Wang D: Enabling silicon for solar-fuel production. Chem Rev 2014, 114:8662-8719.

14. McCrory CCL, Jung S, Ferrer IM, Chatman SM, Peters JC, Jaramillo TF: Benchmarking hydrogen evolving reaction and oxygen evolving reaction electrocatalysts for solar water splitting devices. J Am Chem Soc 2015, 137:4347-4357.

15. Hu S, Lewis NS, Ager JW, Yang J, McKone JR, Strandwitz NC: Thin-film materials for the protection of semiconducting photoelectrodes in solar-fuel generators. J Phys Chem C 2015, 119:24201-24228.

16. Bae D, Seger B, Vesborg PCK, Hansen O, Chorkendorff I: Strategies for stable water splitting via protected photoelectrodes. Chem Soc Rev 2017, 46:1933-1954.

17. Chen S, Wang L-W: Thermodynamic oxidation and reduction potentials of photocatalytic semiconductors in aqueous solution. Chem Mater 2012, 24:3659-3666.

18. Zhang XG: Electrochemistry of Silicon and Its Oxide. Kluwer Academic; 2001.

19. Yu Y, Zhang Z, Yin X, Kvit A, Liao Q, Kang Z, Yan X, Zhang Y, Wang X: Enhanced photoelectrochemical efficiency and stability using a conformal $\mathrm{TiO}_{2}$ film on a black silicon 
photoanode. Nat Energy 2017, 2:17045.

20. Ao X, Tong X, Kim DS, Zhang L, Knez M, He S, Schmidt V: Black silicon with controllable macropore array for enhanced photoelectrochemical performance. Appl Phys Lett 2012, 101:111901.

21. Shaner MR, Fountaine KT, Ardo S, Coridan RH, Atwater HA, Lewis NS: Photoelectrochemistry of core-shell tandem junction $\mathrm{n}-\mathrm{p}^{+}-\mathrm{Si} / \mathrm{n}-\mathrm{WO}_{3}$ microwire array photoelectrodes. Energy Environ Sci 2014, 7:779-790.

22. Santinacci L, Diouf MW, Barr MKS, Fabre B, Joanny L, Gouttefangeas F, Loget G: Protected light-trapping silicon by a simple structuring process for sunlight-assisted water splitting. ACS Appl Mater Interfaces 2016, 8:24810-24818.

23. Chakthranont $\mathrm{P}$, Hellstern TR, McEnaney JM, Jaramillo TF: Design and fabrication of a precious metal-free tandem core-shell $\mathrm{p}^{+} \mathrm{n} \mathrm{Si} / \mathrm{W}$-doped $\mathrm{BiVO}_{4}$ photoanode for unassisted water splitting. Adv Energy Mater 2017, 7:1701515.

24. Hu S, Shaner MR, Beardslee JA, Lichterman M, Brunschwig BS, Lewis NS: Amorphous $\mathrm{TiO}_{2}$ coatings stabilize Si, GaAs, and GaP photoanodes for efficient water oxidation. Science 2014, 344:1005-1009.

25. McDowell MT, Lichterman MF, Carim Al, Liu R, Hu S, Brunschwig BS, Lewis NS: The influence of structure and processing on the behavior of $\mathrm{TiO}_{2}$ protective layers for stabilization of $\mathbf{n}$ -

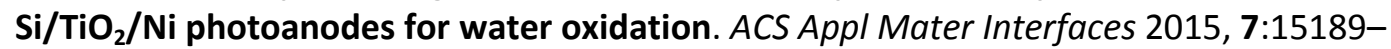
15199.

26. Shaner MR, Hu S, Sun K, Lewis NS: Stabilization of Si microwire arrays for solar-driven $\mathbf{H}_{2} \mathbf{O}$ oxidation to $\mathrm{O}_{2}(\mathrm{~g})$ in $1.0 \mathrm{M} \mathrm{KOH}(\mathrm{aq})$ using conformal coatings of amorphous $\mathrm{TiO}_{2}$. Energy Environ Sci 2015, 8:203-207.

27. Hu S, Richter MH, Lichterman MF, Beardslee J, Mayer T, Brunschwig BS, Lewis NS: Electrical, photoelectrochemical, and photoelectron spectroscopic investigation of the interfacial transport and energetics of amorphous $\mathrm{TiO}_{2} /$ Si heterojunctions. J Phys Chem C 2016, 120:3117-3129.

28. Mei B, Pedersen T, Malacrida P, Bae D, Frydendal R, Hansen O, Vesborg PCK, Seger B, Chorkendorff I: Crystalline $\mathrm{TiO}_{2}$ : a generic and effective electron-conducting protection layer for photoanodes and -cathodes. J Phys Chem C 2015, 119:15019-15027.

29. Chen YW, Prange JD, Dühnen S, Park Y, Gunji M, Chidsey CED, Mclntyre PC: Atomic layerdeposited tunnel oxide stabilizes silicon photoanodes for water oxidation. Nat Mater 2011, 10:539-544.

30. Scheuermann AG, Prange JD, Gunji M, Chidsey CED, Mclntyre PC: Effects of catalyst material and atomic layer deposited $\mathrm{TiO}_{2}$ oxide thickness on the water oxidation performance of metal-insulator-silicon anodes. Energy Environ Sci 2013, 6:2487-2496.

31. Scheuermann AG, Kemp KW, Tang K, Lu DQ, Satterthwaite PF, Ito T, Chidsey CED, McIntyre PC: Conductance and capacitance of bilayer protective oxides for silicon water splitting anodes. Energy Environ Sci 2016, 9:504-516.

32. Scheuermann AG, Lawrence JP, Kemp KW, Ito T, Walsh A, Chidsey CED, Hurley PK, Mclntyre PC: Design principles for maximizing photovoltage in metal-oxide-protected water-splitting photoanodes. Nat Mater 2016, 15:99-105.

33. Quinn J, Hemmerling J, Linic S: Maximizing solar water splitting performance by nanoscopic 
control of the charge carrier fluxes across semiconductor-electrocatalyst junctions. ACS Catal 2018, 8:8545-8552.

34. Digdaya IA, Adhyaksa GWP, Trześniewski BJ, Garnett EC, Smith WA: Interfacial engineering of metal-insulator-semiconductor junctions for efficient and stable photoelectrochemical water oxidation. Nat Commun 2017, 8:15968.

35. Digdaya IA, Trześniewski BJ, Adhyaksa GWP, Garnett EC, Smith WA: General considerations for improving photovoltage in metal-insulator-semiconductor photoanodes. J Phys Chem $C$ 2018, 122:5462-5471.

36. Chen L, Yang J, Klaus S, Lee LJ, Woods-Robinson R, Ma J, Lum Y, Cooper JK, Toma FM, Wang L$\mathrm{W}$, et al.: $\mathbf{p}$-Type transparent conducting oxide/n-type semiconductor heterojunctions for efficient and stable solar water oxidation. J Am Chem Soc 2015, 137:9595-9603.

37. Pijpers JJH, Winkler MT, Surendranath Y, Buonassisi T, Nocera DG: Light-induced water oxidation at silicon electrodes functionalized with a cobalt oxygen-evolving catalyst. Proc Natl Acad Sci USA 2011, 108:10056-10061.

38. Cox CR, Winkler MT, Pijpers JJH, Buonassisi T, Nocera DG: Interfaces between water splitting catalysts and buried silicon junctions. Energy Environ Sci 2013, 6:532-538.

39. Sun K, Shen S, Cheung JS, Pang X, Park N, Zhou J, Hu Y, Sun Z, Noh SY, Riley CT, et al.: Si photoanode protected by a metal modified ITO layer with ultrathin $\mathrm{NiO}_{x}$ for solar water oxidation. Phys Chem Chem Phys 2014, 16:4612-4625.

40. Wang H-P, Sun K, Noh SY, Kargar A, Tsai M-L, Huang M-Y, Wang D, He J-H: High-performance a-Si/c-Si heterojunction photoelectrodes for photoelectrochemical oxygen and hydrogen evolution. Nano Lett 2015, 15:2817-2824.

41. Benck JD, Pinaud BA, Gorlin Y, Jaramillo TF: Substrate selection for fundamental studies of electrocatalysts and photoelectrodes: inert potential windows in acidic, neutral, and basic electrolyte. PLoS One 2014, 9:e107942.

42. Moreno-Hernandez IA, Brunschwig BS, Lewis NS: Tin oxide as a protective heterojunction with silicon for efficient photoelectrochemical water oxidation in strongly acidic or alkaline electrolytes. Adv Energy Mater 2018, 8:1801155.

43. Mei B, Seger B, Pedersen T, Malizia M, Hansen O, Chorkendorff I, Vesborg PCK: Protection of $\mathbf{p}^{+}$-n-Si photoanodes by sputter-deposited Ir/IrO ${ }_{x}$ thin films. J Phys Chem Lett 2014, 5:19481952.

44. Jun K, Lee YS, Buonassisi T, Jacobson JM: High photocurrent in silicon photoanodes catalyzed by iron oxide thin films for water oxidation. Angew Chemie Int Ed 2011, 51:423-427.

45. Strandwitz NC, Comstock DJ, Grimm RL, Nichols-Nielander AC, Elam J, Lewis NS: Photoelectrochemical behavior of $n$-type Si(100) electrodes coated with thin films of manganese oxide grown by atomic layer deposition. J Phys Chem C 2013, 117:4931-4936.

46. Yang J, Walczak K, Anzenberg E, Toma FM, Yuan G, Beeman J, Schwartzberg A, Lin Y, Hettick $M$, Javey $A$, et al.: Efficient and sustained photoelectrochemical water oxidation by cobalt oxide/silicon photoanodes with nanotextured interfaces. J Am Chem Soc 2014, 136:61916194.

47. Qin W, Wang N, Yao T, Wang S, Wang H, Cao Y, Liu S (Frank), Li C: Enhancing the performance of amorphous-Silicon photoanodes for photoelectrocatalytic water oxidation.

ChemsusChem 2015, 8:3987-3991. 
48. Yang J, Cooper JK, Toma FM, Walczak KA, Favaro M, Beeman JW, Hess LH, Wang C, Zhu C, Gul $S$, et al.: A multifunctional biphasic water splitting catalyst tailored for integration with highperformance semiconductor photoanodes. Nat Mater 2016, 16:335.

49. Zhou X, Liu R, Sun K, Papadantonakis KM, Brunschwig BS, Lewis NS: $\mathbf{5 7 0} \mathbf{~ m V ~ p h o t o v o l t a g e , ~}$ stabilized $\mathrm{n}-\mathrm{Si} / \mathrm{CoO}_{\mathrm{x}}$ heterojunction photoanodes fabricated using atomic layer deposition. Energy Environ Sci 2016, 9:892-897.

50. Sun K, McDowell MT, Nielander AC, Hu S, Shaner MR, Yang F, Brunschwig BS, Lewis NS: Stable solar-driven water oxidation to $\mathrm{O}_{2}(\mathrm{~g})$ by Ni-oxide-coated silicon photoanodes. J Phys Chem Lett 2015, 6:592-598.

51. Zhou X, Liu R, Sun K, Friedrich D, McDowell MT, Yang F, Omelchenko ST, Saadi FH, Nielander $A C$, Yalamanchili $S$, et al.: Interface engineering of the photoelectrochemical performance of $\mathrm{Ni}$-oxide-coated $\mathrm{n}$-Si photoanodes by atomic-layer deposition of ultrathin films of cobalt oxide. Energy Environ Sci 2015, 8:2644-2649.

52. Sun K, Saadi FH, Lichterman MF, Hale WG, Wang H-P, Zhou X, Plymale NT, Omelchenko ST, He $\mathrm{J}-\mathrm{H}$, Papadantonakis KM, et al.: Stable solar-driven oxidation of water by semiconducting photoanodes protected by transparent catalytic nickel oxide films. Proc Natl Acad Sci USA 2015, 112:3612-3617.

53. Mei B, Permyakova AA, Frydendal R, Bae D, Pedersen T, Malacrida P, Hansen O, Stephens IEL, Vesborg PCK, Seger B, et al.: Iron-treated NiO as a highly transparent p-type protection layer for efficient Si-based photoanodes. J Phys Chem Lett 2014, 5:3456-3461.

54. Bae D, Mei B, Frydendal R, Pedersen T, Seger B, Hansen O, Vesborg PCK, Chorkendorff I: Backilluminated Si-based photoanode with nickel cobalt oxide catalytic protection layer. ChemElectroChem 2016, 3:1546-1552.

55. Kenney MJ, Gong M, Li Y, Wu JZ, Feng J, Lanza M, Dai H: High-performance silicon photoanodes passivated with ultrathin nickel films for water oxidation. Science 2013, 342:836-840.

56. Han T, Shi Y, Song X, Mio A, Valenti L, Hui F, Privitera S, Lombardo S, Lanza M: Ageing mechanisms of highly active and stable nickel-coated silicon photoanodes for water splitting. J Mater Chem A 2016, 4:8053-8060.

57. Li S, She G, Chen C, Zhang S, Mu L, Guo X, Shi W: Enhancing the photovoltage of Ni/n-Si photoanode for water oxidation through a rapid thermal process. ACS Appl Mater Interfaces 2018, 10:8594-8598.

58. Laskowski FAL, Nellist MR, Venkatkarthick R, Boettcher SW: Junction behavior of $\mathbf{n}-\mathbf{S i}$ photoanodes protected by thin Ni elucidated from dual working electrode photoelectrochemistry. Energy Environ Sci 2017, 10:570-579.

59. Sun K, Ritzert NL, John J, Tan H, Hale W, Jiang J, Moreno-Hernandez IA, Papadantonakis KM, Moffat TP, Brunschwig BS, et al.: Performance and failure modes of Si anodes patterned with thin-film Ni catalyst islands for water oxidation. Sustain Energy Fuels 2018, 2:983-998.

60. Oh S, Oh J: High performance and stability of micropatterned oxide-passivated photoanodes with local catalysts for photoelectrochemical water splitting. J Phys Chem C 2016, 120:133141.

61. Oh S, Song $\mathrm{H}, \mathrm{Oh} \mathrm{J}$ : An optically and electrochemically decoupled monolithic photoelectrochemical cell for high-performance solar-driven water splitting. Nano Lett 2017, 17:5416-5422. 
62. Ji L, Hsu HY, Li X, Huang K, Zhang Y, Lee JC, Bard AJ, Yu ET: Localized dielectric breakdown and antireflection coating in metal-oxide-semiconductor photoelectrodes. Nat Mater 2017, $16: 127-131$

63. Sun K, Park N, Sun Z, Zhou J, Wang J, Pang X, Shen S, Noh SY, Jing Y, Jin S, et al.: Nickel oxide functionalized silicon for efficient photo-oxidation of water. Energy Environ Sci 2012, 5:7872-7877.

64. Contractor $A Q$, Bockris JOM: Investigation of a protective conducting silica film on $\mathbf{n}$-silicon. Electrochim Acta 1984, 39:1427-1434.

65. Yu X, Yang P, Chen S, Zhang M, Shi G: NiFe alloy protected silicon photoanode for efficient water splitting. Adv Energy Mater 2017, 7:1-6.

66. Dong WJ, Song YJ, Yoon H, Jung GH, Kim K, Kim S, Lee J-L: Monolithic photoassisted water splitting device using anodized Ni-Fe oxygen evolution catalytic substrate. Adv Energy Mater 2017, 7:1700659.

67. Tung RT: The physics and chemistry of the Schottky barrier height. App Phys Rev 2014, 011304.

68. Ohdomari I, Aochi H: Size effect of parallel silicide contact. Phys Rev B 1987, 35:682-686.

69. Freeouf JL, Jackson TN, Laux SE, Woodall JM: Size dependence of "effective" barrier heights of mixed-phase contacts. J Vac Sci Technol 1982, 21:570-573.

70. Tung RT: Electron transport of inhomogeneous Schottky barriers. Appl Phys Lett 1991, 58:2821-2823.

71. Yae S, Tsuda R, Kai T, Kikuchi K, Uetsuji M, Fujii T, Fujitani M, Nakato Y: Efficient photoelectrochemical solar cells equipped with an $n$-Si electrode modified with colloidal platinum particles. J Electrochem Soc 1994, 141:3090-3095.

72. Nakato $\mathrm{Y}$, Tsubomura $\mathrm{H}$ : Silicon photoelectrodes modified with ultrafine metal islands. Electrochim Acta 1992, 37:897-907.

73. Rossi RC, Lewis NS: Investigation of the size-scaling behavior of spatially nonuniform barrier height contacts to semiconductor surfaces using ordered nanometer-scale nickel arrays on silicon electrodes. J Phys Chem B 2001, 105:12303-12318.

74. Fabre B: Functionalization of oxide-free silicon surfaces with redox-active assemblies. Chem Rev 2016, 116:4808-4849.

75. Hill JC, Landers AT, Switzer JA: An electrodeposited inhomogeneous metal-insulatorsemiconductor junction for efficient photoelectrochemical water oxidation. Nat Mater 2015, 14:1150-1155.

76. Loget G, Fabre B, Fryars S, Mériadec C, Ababou-Girard S: Dispersed Ni nanoparticles stabilize silicon photoanodes for efficient and inexpensive sunlight-assisted water oxidation. ACS Energy Lett 2017, 2:569-573.

77. Oh K, Mériadec C, Lassalle-Kaiser B, Dorcet V, Fabre B, Ababou-Girard S, Joanny L, Gouttefangeas $F$, Loget $G$ : Elucidating the performance and unexpected stability of partially coated water-splitting silicon photoanodes. Energy Environ Sci 2018, 11:2590-2599.

78. Lee SA, Lee TH, Kim C, Lee MG, Choi M-J, Park H, Choi S, Oh J, Jang HW: Tailored $\mathbf{N i O}_{\mathbf{x}} / \mathbf{N i}$ cocatalysts on silicon for highly efficient water splitting photoanodes via pulsed electrodeposition. ACS Catal 2018, 8:7261-7269. 
79. Xu G, Xu Z, Shi Z, Pei L, Yan S, Gu Z, Zou Z: Silicon photoanodes partially covered by $\mathrm{Ni@Ni(OH})_{2}$ core-shell particles for photoelectrochemical water oxidation. ChemSusChem 2017, 10:2897-2903.

80. Stevens MB, Enman LJ, Batchellor AS, Cosby MR, Vise AE, Trang CDM, Boettcher SW: Measurement techniques for the study of thin film heterogeneous water oxidation electrocatalysts. Chem Mater 2017, 29:120-140.

81. Tung CW, Chuang Y, Chen HC, Chan TS, Li JY, Chen HM: Tunable electrodeposition of Ni electrocatalysts onto Si microwires array for photoelectrochemical water oxidation. Part Part Syst Charact 2018, 35:1700321.

82. Kasemthaveechok S, Oh K, Fabre B, Bergamini J-F, Mériadec C, Ababou-Girard S, Loget G: A general concept for solar water-splitting monolithic photoelectrochemical cells based on earth-abundant materials and a low-cost photovoltaic panel. Adv Sustain Syst 2018, 2:1800075.

83. Zhao J, Gill TM, Zheng X: Enabling silicon photoanodes for efficient solar water splitting by electroless-deposited nickel. Nano Res 2018, 11:3499-3508.

84. Chen J, Xu G, Wang C, Zhu K, Wang H, Yan S, Yu Z, Zou Z: High-performance and stable silicon photoanode modified by crystalline Ni@ amorphous Co core-shell nanoparticles. ChemCatChem 2018, 10:5025. 